\title{
ASSALTO AO TURNO EM INTERAÇÕES ASSIMÉTRICAS DE GÊNERO: DISPUTA E COOPERAÇÃO
}

\author{
(Turn-taking in cross-sex interactions: dispute and cooperation)
}

\author{
Raquel Meister Ko Freitag ${ }^{1}$ \\ Universidade Federal de Sergipe \\ Rebeca Rodrigues de Santana ${ }^{2}$ \\ Universidade Federal de Sergipe
}

\begin{abstract}
RESUMO
$O$ assalto ao turno consiste em entradas não consentidas ou não requeridas no turno do interlocutor, indicando disputa pela fala ou colaboração entre parceiros conversacionais. Neste estudo, observamos como se dá o processo de assalto ao turno em interações assimétricas quanto ao sexo/gênero dos interactantes, em ambiente universitário. Tomamos como amostra para tratamento qualitativo três interações da amostra de fala Redes Sociais de Informantes Universitários de Itabaiana/SE. Os resultados apontam que o trabalho interacional de homens e mulheres é diferenciado, o que se evidencia por meio dos recursos linguísticos empregados pelos interactantes, como os marcadores discursivos interacionais e com as posturas de assalto ao turno.
\end{abstract}

Palavras-chave: Assalto ao turno, gênero, interação.

\begin{abstract}
The turn-taking refers to entries not consented or not required in the turn of the interlocutor, indicating dispute for the speech or collaboration between conversational partners. This study investigates how the assault process occurs in the shift in cross-sex interactions in a university context. The sample is Social Networks of Undergraduates of Itabaiana/SE, in qualitative approach. The results show that the interactional work of men and women is differentiated, which is evidenced by the linguistic resources used by the speakers, such as discourse markers and the turn-taking stances.
\end{abstract}

Keywords: Turn-taking, gender, interaction.

Recebido em: agosto 2018

Aceito em: março 2019

DOI: $10.26512 /$ les.v20i1.11254

\section{INTRODUÇ̃̃o}

As diferenças de performance linguística entre homens e mulheres podem ser vistas como evidência da dominância e da diferença, pelo viés do déficit (LAKOFF, 1973/2010), da submissão (COATES, 1998), do comportamento típico (TANNEN, 1991) ou transgressor (CAMERON, 1998). ${ }^{3}$

\footnotetext{
${ }^{1}$ Professora do Departamento de Letras Vernáculas, do Programa de Pós-Graduação em Letras e do Programa de PósGraduação em Psicologia da Universidade Federal de Sergipe. Graduada em Letras, mestre e doutora em Linguística pela Universidade Federal de Santa Catarina, área de concentração Sociolinguística.

${ }^{2}$ Mestre e graduada em Letras pela Universidade Federal de Sergipe. Membro do Grupo de Estudos em Linguagem Interação e Sociedade - GELINS.

${ }^{3}$ No título deste artigo, vinculamos os papéis que homens e mulheres assumem no turno interacional ao rótulo de gênero, por entendermos que são construídos social e culturalmente, e não atributos biológicos. Esta é uma discussão que vem
} 
Diferentes recursos linguísticos têm sido identificados para validar essas evidências. São elencados os usos linguísticos que predominam na fala de homens e de mulheres, sejam itens específicos, como marcadores discursivos (CARLI, 1990; REID; KEERIE; PALOMARES, 2003), sejam padrões de comportamento em interações (WEST; ZIMMERMAN, 1983).

$\mathrm{Na}$ abordagem de dominância, as diferenças são interpretadas como dominação masculina e subordinação feminina, o que, em termos de comportamentos interacionais, pode ser reinterpretado como competição e colaboração: "homens são, por natureza ou condicionamento social, mais competitivos e que as mulheres são mais cooperativas" (COULTHARD, 1991, p. 48). Em contextos interacionais, Zimmerman e West (1987/2010), ao analisar interações entre pessoas de diferentes e iguais gêneros, constataram que, independentemente da proximidade social em interações de pares mistos, os homens realizam muito mais interrupções - entendidas aqui como assaltos ao turno, como veremos mais à frente - que as mulheres, e, em interações de pares de igual gênero, não há diferença no número de interrupções. Com base nesses resultados, os autores afirmam que "os homens recusam uma posição igualitária das mulheres enquanto parceiras conversacionais" (ZIMMERMAN; WEST, 1987/2010, p. 57).

A característica competitiva dos homens também é destacada por Deborah Tannen (1990/2010), ao destacar que eles encaram a conversa como uma competição, por isso não demonstram interesse em apoiar as falas alheias e sim em mudar o rumo da conversa para ocupar o papel principal "contando uma história, ou piada, ou demonstrando conhecimento" (TANNEN, 1990/2010, p. 92).

A fala é resultado da atividade interacional entre os participantes de uma conversa, considerando-se interação, em sociedade, como a "reciprocidade do comportamento das pessoas, quando em presença umas das outras, numa escala que vai da cooperação ao conflito" (GALEMBECK; COSTA, 2009, p. 1938), sendo a conversa sinônimo de troca, de interlocução, que pressupõe um jogo de influências recíprocas que se constituem a partir do envolvimento dos participantes no diálogo, "que devem se mostrar receptivos e ativos na conversa, dando sinais de entendimento ou não, de concordância, de desinteresse, de dúvida etc.” (JUNG; MAREGA, 2011, p. 321).

sendo incorporada à Sociolinguística Variacionista, linha de trabalho das pesquisadoras autoras desse artigo, desde a década de 1990 (ECKERT, 1989; LABOV, 1990) e mais recentemente à abordagem desenvolvida no Brasil (FREITAG, 2015; FREITAG; SEVERO, 2015), considerando as escolhas e usos linguísticos como efeitos da construção de uma dada identidade em um dado contexto e com uma certa finalidade, de modo que a variável tem sido denominada de "sexo/gênero" por conta de recobrir muito mais do que a dimensão biológica (também existente no âmbito da linguagem), mas também os papéis sociais desempenhados por homens e mulheres. Na amostra utilizada no presente estudo, o controle da identificação de gênero dos interactantes considerou o gênero civil, ou seja, como o indivíduo se apresenta socialmente em função dos paradigmas sociais existentes, como preencher um formulário governamental. Por isso, assumimos a perspectiva de homens e de mulheres. 
A conversa pressupõe a alternância nos papéis de falante e ouvinte, que é chamada de troca de turnos, entendendo-se por turno qualquer intervenção dos participantes do diálogo, de qualquer extensão, tanto as que apresentam valor referencial ou informativo, chamadas de turnos nucleares, como as intervenções curtas, indicadoras de que um dos interlocutores está acompanhando o que é dito por seu parceiro conversacional, denominadas turnos inseridos (GALEMBECK; COSTA, 2009, p. 1940). Tal alternância pode ocorrer por meio de dois processos: passagem e assalto. A passagem de turno pode ser requerida, sendo marcada linguisticamente por uma pergunta "ou pela presença de marcadores que testam a atenção ou buscam a confirmação do ouvinte” (GALEMBECK, 1999, p. 72), como é o caso de “né?”, “não é?" “sabe?”, “entende?”, ou consentida, "uma entrega implícita: o ouvinte intervém e passa a deter o turno, sem que o concurso tenha sido diretamente solicitado" (GALEMBECK, 1999, p. 74) .

$\mathrm{O}$ assalto ao turno "é marcado pelo fato de o ouvinte intervir sem que a sua participação tenha sido direta ou indiretamente solicitada. Em outras palavras, o ouvinte 'invade o turno do falante" (GALEMBECK, 1999, p. 74); segundo Galembeck (1999), este processo pode ocorrer quando há hesitação (pausa, alongamento, repetição etc.) por parte do falante, e o ouvinte aproveitase disso para intervir - assalto com "deixa"; ou quando há uma entrada brusca por parte do ouvinte no turno - assalto sem "deixa”.

A fim de contribuir para os estudos linguísticos que relacionam usos linguísticos e padrões de comportamento de gênero, observamos como se dá o processo de assalto ao turno em interações assimétricas quanto ao gênero dos interactantes, em ambiente universitário, por entendermos que a passagem e o assalto ao turno são sensíveis ao contexto sociocultural (cf. SANTANA, 2018) e que outros fenômenos linguísticos analisados neste mesmo grupo apontam para diferenças de comportamento quanto ao gênero, a exemplo de marcadores discursivos interacionais (FREITAG; SILVA; EVANGELISTA, 2017).

Tendo em vista que as situações de assalto podem indicar uma competição pelo turno, os homens, por serem considerados mais competitivos em contextos de fala, realizariam mais o assalto ao turno que as mulheres. No entanto, atentando para a necessidade, ressaltada por Deborah Tannen (1990/2010), de não apenas contar o número de interrupções, mas também observar o conteúdo da conversa em que elas ocorrem, "sobre o que as pessoas estavam falando, as intenções dos falantes, suas relações uns com os outros, e que efeito a interrupção teve na conversa” (TANNEN, 1990/2010, p. 68), analisamos os assaltos ao turno quanto à postura do falante, ao domínio do tópico, à proximidade ou distância social entre os falantes e ao tipo de assalto. Tomamos como amostra para tratamento qualitativo, na perspectiva da fala em interação (OSTERMANN, 2012) três interações da 
amostra de fala Redes Sociais de Informantes Universitários de Itabaiana/SE (ARAUJO; SANTOS; FREITAG, 2014), pertencente ao Banco de Dados Falares Sergipanos (FREITAG, 2013).

Este tipo de amostra consiste na documentação linguística de interações conduzidas, com temas sugeridos acerca de tópicos diversificados, que vão desde assuntos neutros àqueles que envolvem a preservação de faces positiva e negativa (que, no presente trabalho, retomaremos como assuntos mais impositivos ou menos impositivos), para que em cada interação um interactante escolhesse 10 cartões e, a partir da situação apresentada no cartão, identificasse o tema abordado e conduzisse a conversa com o seu parceiro conversacional, estando este interactante, neste momento, com o domínio do tópico na interação.

Esta amostra tem como parâmetro constitutivo o controle da distancia social entre os interactantes, tendo em vista que "se um indivíduo tem um grau de proximidade forte com um interlocutor e fraco com outro, seu comportamento linguístico na interação com cada um deles é, provavelmente, diferente em decorrência do tipo de relacionamento" (ARAUJO; SANTOS; FREITAG, 2014, p. 102), fator também considerado no presente trabalho, em interações assimétricas quanto ao gênero dos interactantes, a fim de verificar se essa diferença de comportamento também ocorre em um fenômeno da conversa, o assalto ao turno.

As três interações utilizadas como corpus para o presente trabalho têm duração média de 40 minutos cada, e são assimétricas quanto ao gênero dos parceiros conversacionais: uma delas ocorre entre um homem e uma mulher próximos socialmente em que a mulher está com o domínio do tópico (a interação entre Ama e Dav); outra entre o homem da primeira interação e uma mulher de quem ele é distante socialmente em que ele dispõe do domínio do tópico (a interação entre Dav e Jos); e a última entre a mulher da primeira e um homem de quem ela é distante socialmente em que ela não dispõe do domínio do tópico (a interação entre Ama e Wag).

A amostra de fala Redes Sociais de Informantes Universitários de Itabaiana/SE (ARAUJO; SANTOS; FREITAG, 2014) tem sido utilizada para discussões relacionadas aos efeitos de gênero em abordagens sociolinguísticas (cf. FREITAG; SEVERO, 2015; FREITAG, 2015) e cujo desenho de coleta tem sido replicado para abordar outros fenômenos que são variáveis quanto à assimetria, hierarquia e papel de gênero, como Santana (2019), que analisa a construção tipo em uma comunidade de práticas universitária, seguindo os mesmos princípios de coleta.

\section{Assalto ho turno}

Com base no conceito de "postura do falante", apresentado por Macedo e Silva (1996) quanto ao uso de marcadores discursivos iniciadores de turno (confirmação, negação/dúvida, 
enumeração e lembrança), identificamos seis posturas para o assalto ao turno nas interações: confirmação, negação, completar a fala do outro, justificativa, mudança de tópico e indagação.

O excerto (1) é um exemplo do que consideramos como uma postura de confirmação, pois é um contexto em que o assalto ao turno é realizado para concordar com o que está sendo dito pelo falante em curso. Nesse exemplo, a mulher realiza o assalto para confirmar o que é dito por seu parceiro conversacional a respeito do tópico emprestar dinheiro.

(1) Homem: sim (amanhã) já foi essa mesmo você empresta a uma pessoa que é sua amiga mas depois ela não lhe paga... aí fica com raiva de você porque você porque ela não pagou a você... eu nunca vi em vez de eu ficar com raiva dela porque ela não me pagou ela é quem fica com raiva de mim porque ela não me pagou $\left[{ }^{4}\right.$

Mulher: é... é fica de mal fica de mal não fala quem tinha que ter até mesmo às vezes quem emprestou e não recebeu que fica com vergonha né? e aquela outra pessoa não tem vergonha e ainda fica de mal e não fala

Já o excerto (2) apresenta um exemplo do que consideramos como postura de negação, pois o assalto é utilizado para negar algo que é dito no turno anterior. Nesse exemplo, o homem realiza o assalto para negar a informação apresentada por sua parceira conversacional de que ele estaria feliz com o término do seu curso de graduação.

(2) Mulher: eu acho que aí é uma coisa de momento né? eu acho que só no momento mesmo da situação pra gente saber como é que realmente a gente ia reagir... mas você está terminando o curso está feliz né? vai ficar de férias [

Homem: eu não eu não tô feliz

Em (3), temos um exemplo do que consideramos como postura de completar a fala do outro, uma vez que o assalto foi utilizado em um contexto de complementar o que estava sendo dito pelo interlocutor, o que, na maioria dos casos, se deu quando o falante em curso deixou evidente que estava realizando o planejamento verbal. Nesse exemplo, a mulher realizou o assalto ao turno quando o homem deu pistas de que estava na busca de palavras para completar a sua fala sobre as manifestações, auxiliando-o, assim, nesse processo.

(3) Homem: as manifestações eu acredito que deve que são legítimas... devem ser legítimas... mas eu a eu acho que há uma questão complicada dessas manifestações... no ponto de que não se não há um debate sobre o que está sendo manifestado... sobre o que está sendo manifestado... ninguém se ninguém senta... (hes) até mesmo na academia ou no... na sociedade pra discutir essas todas essas questões que estão sendo reivindicadas... como a

\footnotetext{
${ }^{4}$ Sinal de transcrição adotado pelo Banco de Dados Falares Sergipanos (FREITAG, 2013) para marcar sobreposição de vozes.
} 
questão da educação como a questão da saúde como a questão da da segurança... não se não há... (hes) essa essa esse diálogo essa discussão sobre qual o o caminho seria mais viável... (hes) pra solucionar esse problema... e você manifestar por manifestar... é algo é... é algo como é

Mulher: que não tem valor né?

Já o excerto (4) é um exemplo da postura que consideramos como de justificativa, pois o assalto ao turno foi realizado numa tentativa de justificar algo dito em um turno anterior. Nesse exemplo, a mulher assalta o turno para informar a razão pela qual, para ela, a cura gay pode ser descartada, como ela já havia dito em um turno anterior.

(4) Mulher: eu penso que sim né? podemos descartar né? essa parte da cura

Homem: mas se você não compreende qual é o problema como é que podemos descartar alguma

Mulher: se eu não compreendo então eu descarto né? essa parte de da da cura... se eu não compreendo a cura gay então eu posso descartar a parte da cura ((RISOS))

Em (5), temos um exemplo do que consideramos como postura de mudança de tópico, uma vez que o assalto ao turno é utilizado para mudar o assunto abordado pelo falante em curso. Nesse exemplo, o homem realiza o assalto para propor uma troca do assunto que estava sendo inserido, $a$ seca no nordeste, para um assunto relacionado a um amigo em comum, convidando sua interlocutora a visitar esse amigo.

(5) Mulher: sobre essa questão do rio São Francisco que é pra poder Homem: cê quer ir pra casa de Edvaldo? quer?

Já no excerto (6), temos um exemplo do que consideramos como postura de indagação, pois o assalto ao turno foi utilizado para realizar uma pergunta ao interlocutor. Nesse exemplo, o homem faz o uso do assalto para fazer uma indagação sobre uma afirmação dita anteriormente por sua interlocutora sobre o assunto bolsa família.

(6) Mulher: mas geralmente as pessoas que recebem o os o Bolsa Família... é porque tem crianças... crianças que são

Homem: mas será só que é só crianças que vão pra... pra escola ou pra instituição de ensino só pra aprender? quem é que vai pra instituição de ensino pra aprender?

Como resultado geral das três interações analisadas, identificamos 29 ocorrências de assalto ao turno, sendo 6 com postura de confirmação, 5 realizados pela mulher e um pelo homem; 4 com postura de negação, 3 realizadas pelo homem e um pela mulher; 6 com postura de completar a fala do outro, 4 realizados pela mulher e 2 pelo homem; 2 com postura de justificativa realizados pela 
mulher; 2 com postura de mudança de tópico realizados pelo homem; e 9 com postura de indagação, 8 realizados pelo homem e um pela mulher, gráfico 1 .

Gráfico 1 - Postura do falante no assalto ao turno quanto ao gênero dos interactantes.

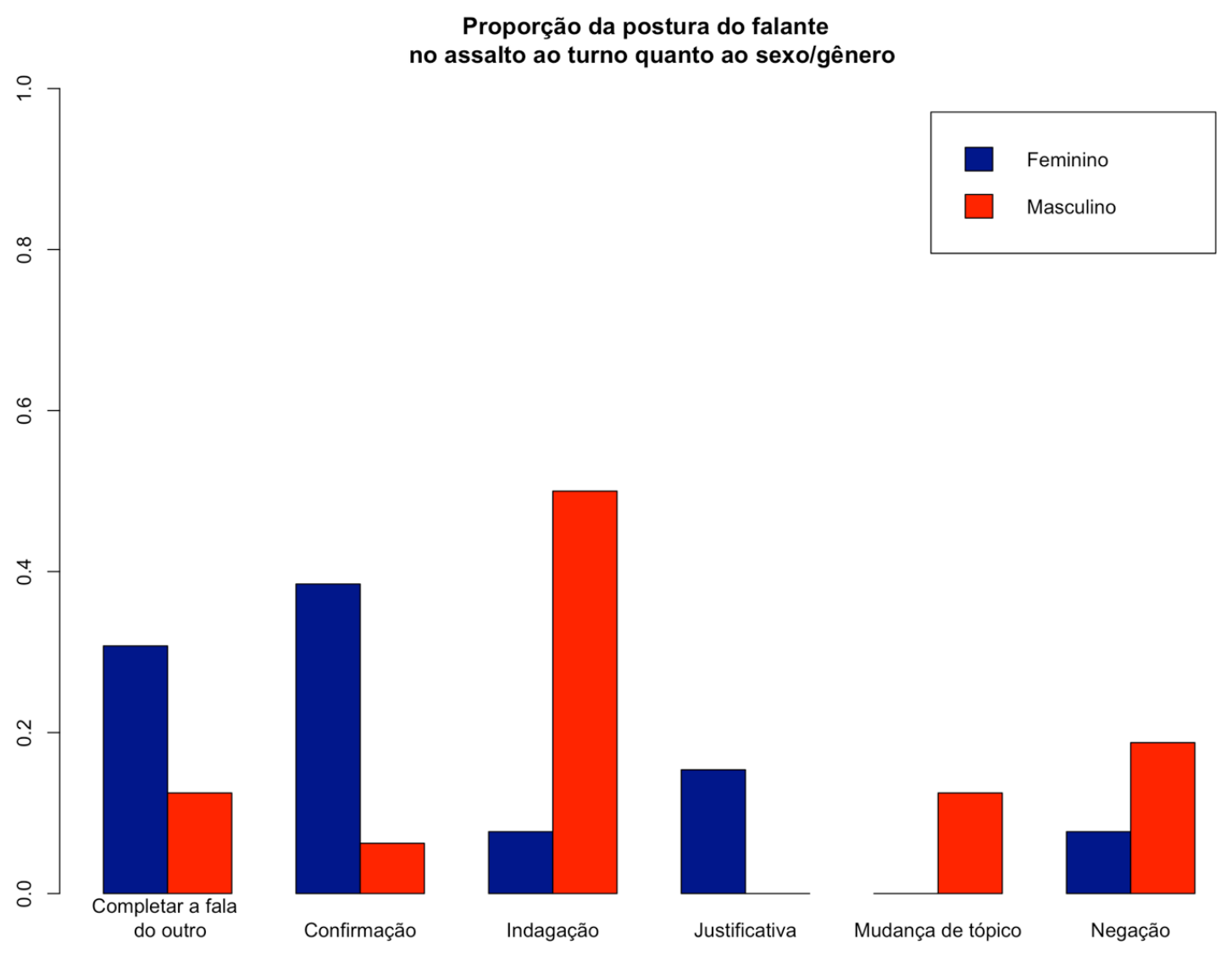

Fonte: elaborado pela autora

Os resultados globais apontam que mulheres assumem uma postura mais colaborativa, ao completar a fala do outro interactante, confirmar e justificar, no processo de tomada de turno. Já os homens, lançam dúvida, mudam ou negam o tópico. As proporções gerais reforçam as premissas de Tannen (1990/2010) de que homens são competitivos e mulheres colaborativas nas interações.

Vejamos agora detalhadamente cada interação. A primeira interação analisada é composta por um diálogo entre um homem e uma mulher, que aqui chamaremos de Dav e Ama respectivamente, e que têm uma relação de proximidade social. Por meio da análise, foi possível constatar 14 ocorrências de assalto, sendo 8 realizados pelo homem e 6 pela mulher. Embora a quantidade de ocorrências tenha sido pouco expressiva do ponto de vista quantitativo, os contextos analisados revelam comportamentos que corroboram com o que tem sido descrito pelos estudos de gênero. 
Em relação à postura do falante, a mulher realizou assaltos ao turno em contextos de completar o turno do outro, 3 ocorrências; de confirmação, 2 ocorrências; e de indagação, uma ocorrência. Os excertos (7), (8), (9), respectivamente, exemplificam tais contextos.

(7) Dav: é como é que ela não fala [

Ama: é verdade

Dav: como é que o cara vai emprestar de novo? ((RISOS))

(8) Dav: depende... depende a situação né? depende a situação porque eu conheço uma amiuma... uma amiga que... ela ficou sabendo que o pai dela traiu... trairi- trai- estava traindo a mãe... mas só que a mãe ela tá ela saiu da da ela teve um der- um derrame... o AVC né? o AVC... (hes) há um mês... atrás... quer dizer como é que você conta nessa situação? eu acho que de- deve muito ver essa que essa... a situação que está... [

Ama: ocorrendo

Dav: ocorrendo... cê faria o quê?

(9) Ama: quando saía pra algum lugar assim com eles pra passear pra ir pro cinema o teatro pra algum lugar assim vocês você aprontava muito ou sempre se comportava direitinho?

Dav: eu sempre me comportava ia pra [

Ama: tudo que via queria... se fosse pra comprar alguma coisa assim?

Em (7), enquanto o falante homem expõe sua opinião a respeito do assunto emprestar dinheiro, a falante mulher insere o turno "é verdade" para concordar com o que está sendo dito por ele. Já em (8), Ama realiza uma entrada não requerida enquanto Dav, ao tratar do assunto traição do pai, está em um processo de planejamento verbal, buscando uma palavra adequada, e logo depois do assalto ele retoma o turno deixando evidente que a palavra indicada pela parceira conversacional contribuiu com o conteúdo informacional do seu turno anterior. E, em (9), a mulher realiza um assalto como uma forma de complementar a indagação feita em seu turno anterior. Essas três posições da falante, ao realizar entradas não consentidas, ou não requeridas, parecem indicar uma postura colaborativa, pois contribuem com o desenvolvimento do tópico por parte do seu parceiro conversacional, demostrando que está de acordo com o que está sendo dito, que está engajada na conversa a ponto de prever o que será dito, e que quer que ele fale mais sobre determinado assunto.

Já a postura do falante homem ao realizar o assalto ao turno foi de negação, em 3 ocorrências; indagação, também em 3 ocorrências; e mudança de tópico, em 2 ocorrências. Os excertos (10), (11) e (12) exemplificam, respectivamente, essas posturas.

(10) Ama: você não tinha nenhum primo assim nem um amiguinho um irmão? que ficava brigando pelo... quem ficava com o controle pra poder assistir desenho ou... a questão de querer ser o Super-homem ou Batman ficava brigando por ser algum dos... personagens de desenho? 
Dav: não briga briga assim muito eu não tinha não porque era eu ia sempre... quando eu vinha com os meus primos eu ia sempre pra casa de minha vó né? aí sabe... ou um se(hes)... o mais velho... aí pronto quer paparicar né? nunca vi... até hoje quando eu vou pra casa de minha vó é... é triste "senta meu filho cê come é o que tiver senta senta... né pra fazer não é pra levantar da mesa... senta"... ((RISOS))

Ama: então você você é um neto que tem muita sorte né David? então falando de sorte Dav: sorte? nós levava era xinga que só o castigo... quando ia pra casa de meu bisavô... uma vez... foi pra casa de meu bisavô... aí juntou os primo tudo... logo de família grande tem uma ruma de primo tinha uma base de uns oito... aí lá vai... menino é o castigo quer ficar tudo agarrado... vamo dormir... e pra ir e pra definir o lugar de cada um e pra dormir? tinha só tinha uma cama de casal... e um queria ficar perto do outro... aí pronto foi os oito lá na cama de casal... mas eu não dormi não... era pé e era mão era tudo na cara do cara... quando um tava cochilando... chegava um pé tome... me deu uma pancada e o fedor... de chulé... nunca vi

(11) Ama: que às vezes assim né? tem pessoas que não tem nem como controlar essa questão de gases e às vezes tá em determinado ambiente né? com muita gente assim ao redor e não sabe se controlar... pra poder sair né? quiser [

Dav: cê é dessas pessoas impulsivas?

(12) Ama: sobre essa questão do rio São Francisco que é pra poder

Dav: cê quer ir pra casa de Edvaldo? quer?

(13) Ama: fazer o que lá menino?

Dav: passear

Ama: ah... isso aí já é outro assunto vamos terminar aqui...

Dav: é Edvaldo tá precisando de gente pra ir passear lá viu?

Ama: ah viu ((RISOS))... que bom... sobre a questão assim da seca no nordeste né? a gente cansa de ver sobre essa temática seca no nordeste seca no nordeste... no nordeste e nunca houve um problema uma solução realmente pra solucionar essa seca né? um alguns queriam colocar a questão da transposição que seria que alguns estados não deixariam de ser beneficiado mas que não chegou nem ser concretizado como é que você vê essa questão da seca no nordeste? sempre mas nunca foi solucionado

Dav: a seca é um problema no nordeste?

Ama: responda

Dav: responda

Ama: ( ) muitos colocam né? que a gente vê

Em (10), podemos perceber que, embora haja um tom de pergunta, Dav faz uma negação de forma exclamativa, discordando da conclusão à qual Dan chegou sobre sua infância e após a discordância, ele narra fatos para justificá-la. Já em (11), ele realiza uma pergunta, tratando de forma bastante direta um assunto impositivo, que é o de problemas intestinais, diferentemente da sua parceira conversacional, que utiliza marcadores discursivos, como o “assim" e o "né?", para atenuar a imposição do assunto. E, em (12), há um assalto para mudança de assunto, que pode indicar uma tentativa de domínio do tópico por parte do homem, que parece recusar o que sua parceira conversacional deseja inserir, a seca no nordeste. Ela só consegue inseri-lo após enfrentar a 
resistência por parte dele, como ilustra o excerto (13) cujos turnos seguem os do excerto (12), contexto que também marca a outra ocorrência de assalto para mudança de tópico; o turno "é Edvaldo tá precisando de gente pra ir passear lá viu?”.

Com relação ao domínio do tópico, embora nessa interação Ama estivesse no domínio, dispondo dos cartões que orientaram os assuntos a serem tratados, foi Dav que mais realizou o assalto. Mas, sobre esse aspecto, cabe ressaltar que, mesmo o domínio não tendo sido designado a ele, houve tentativas de dominar por sua parte, como exemplificado nos excertos (12) e (13), já mencionados, em que isso ocorreu por meio de assalto ao turno para mudança de tópico. No excerto (11), ele a interrompe para lhe fazer uma pergunta enquanto ela insere o tópico; como também (14), em que ele, após responder a uma pergunta sobre o programa Bolsa Família, interrompe o comentário da mulher para lhe devolver a pergunta.

(14) Ama: falando nessa questão de... de resolver até mesmo os os problemas né? a questão que coloca a boa alimentação sabe que por outro lado não... possibilita isso... a questão da Bolsa Família... é uma medida... você acha que vai... acabar com a pobreza com a miséria no Brasil? e quais são os benefícios que você acha ou que não tem benefício algum a questão da Bolsa Família?

Dav: a questão da bolsa família a bolsa família ela é uma questão muito com... (hes) com fe- (hes) problemática... por quê? porque ela se depara na na realidade de que... uma pessoa que não tem... (hes) meios de sobre... (hes) de ter uma uma condição de sobrevivência... essa bolsa família traz pra ela essa essa... essa medida... de... de permanecer vivo... porque é é essa Bolsa Família não traz... (hes) condições pra que essa po- pra que esse indivíduo que recebe... possa re- é se reproduzir socialmente... dentro de uma condição digna... essa bolsa família traz muito essa questão da da da alienação de que um povo é conduzido a... depender e perpetuar essa questão do patrimonialismo e do patriarcalismo... que tanto... (hes) Ana Rocha discutia na sala de aula ((TOSSE))... onde onde você é ne- onde... (hes) onde há necessidade de você... dar... (hes) a quem necessita... um alimento que deveria ser por... por lei algo garantido e está garantido na constituição... pois todos somos livres somos... (hes) temos o direito a liberdade a igualdade a educação a moradia a alimentação está na constituição... mas ao mesmo tempo essa constituição é contraditória porque não dá à população condições pra que ela se reproduza socialmente... e essa condição pra ela se reproduzir está através do trabalho... não existe trabalho nessa suficiente pra que essa população tenha essa condição de de de... de de não mendigar ao estado... e que essa mendi- e que essa mendigação está intimamente ligada à questão da pobreza... e que essa pobreza é útil pro estádio pro estado pra que se per- pra que se perpetue essa lógica da da subordinação... do patrimonialismo eu lhe dou a Bolsa Família pra que você dê futuramente o voto pra mim

Ama: é o que a gente

Dav: você acha você acha você como é que você vê essa questão da Bolsa Família?

A situação de devolução da pergunta que ocorreu no excerto (14) foi bastante recorrente, mesmo em situações em que não houve assalto, nas quais Ama realizava a passagem do turno para 
que Dav respondesse a uma pergunta e ele, por sua vez, a retornava para ela, como ocorreu em (13), em que ele devolve a pergunta sobre a seca no nordeste, e também no excerto (15).

(15) Ama: (...) o que você tem a dizer sobre a questão das manifestações porque assim... alguns vão pra lutar mesmo outros vão pra... bagunçar pra não dar nenhuma importância né?

Dav: cê acha correto as manifestações?

Ama: você acha correto?

Dav: cê acha?

Ama: você acha? responda ((RISOS))

Dav: ((RISOS))

Ama: eu que fiz a pergunta

Dav: hein?

Ama: responda você

Dav: as manifestações eu acredito que deve que são legítimas... devem ser legítimas... mas eu a eu acho que há uma questão complicada dessas manifestações... no ponto de que não se não há um debate sobre o que está sendo manifestado... sobre o que está sendo manifestado... ninguém se ninguém senta... (hes) até mesmo na academia ou no... na sociedade pra discutir essas todas essas questões que estão sendo reivindicadas... como a questão da educação como a questão da saúde como a questão da da segurança... não se não há... (hes) essa essa esse diálogo essa discussão sobre qual o o caminho seria mais viável... (hes) pra solucionar esse problema... e você manifestar por manifestar... é algo é... é algo como é?

Em (15), podemos perceber que, mesmo não tendo os cartões que continham os tópicos a serem abordados na interação, há uma tentativa por parte de Dav em dominar o tópico, resistindo a responder à pergunta e devolvendo-a repetidas vezes para sua interlocutora, e só depois de uma certa insistência, ele desenvolve um turno relativamente longo sobre as manifestações.

Quanto ao tipo de assalto ao turno realizado, consideramos os dois propostos por Galembeck (1999): (i) o assalto com deixa, que pode ocorrer quando há hesitação (pausa, alongamento, repetição etc) por parte do falante, e o ouvinte aproveita-se disso para intervir, e (ii) o assalto sem deixa, que ocorre quando há uma entrada brusca por parte do ouvinte no turno. Na análise, 5 das ocorrências foram de assaltos com deixa e 8 de assaltos sem deixa; dessas a mulher realizou 3 ocorrências tanto do primeiro quanto do segundo tipo, enquanto o homem realizou 2 de assalto com deixa e 5 sem deixa. Assim, o homem realizou mais vezes as entradas bruscas no turno de sua interlocutora, que, por sua vez, alternou mais entre esse tipo de entrada e as que ocorrem mediante a hesitação do parceiro conversacional.

A segunda interação analisada é um diálogo entre o falante homem da interação anterior, Dav, e uma mulher, Jos, com a qual ele não mantinha uma relação de proximidade social, que ele não 
conhecia antes da gravação. Outro ponto distinto é que, desta vez, Dav dispôs dos cartões com os assuntos a serem abordados, estando, assim, com o domínio do tópico.

Por meio da análise, foi possível constatar 8 ocorrências de assalto ao turno nessa interação, 5 realizadas pelo homem e 3, pela mulher. Tais ocorrências estão distribuídas em 4 assaltos com postura de indagação e um de negação realizados pelo homem; e 2 assaltos para justificativa e um para completar a fala do outro, realizados pela mulher. Os excertos (16) e (17) exemplificam, respectivamente, os assaltos para indagação e negação realizados pelo falante homem.

(16) Jos: sim os tempos são outros mas... esse tempo pra mim eu... não gosto não acho legal... uma criança de quatro anos tá com um computador... você não acharia mais interessante Dav: e que idade e que idade que você delimi- você delimitaria pra uma criança usar um computador?

Em (16), podemos perceber o assalto ao turno sendo realizado por Dav em um contexto em que Jos expõe sua opinião sobre o acesso de crianças à internet, o que ocorre por meio de uma postura de indagação a respeito da idade necessária para o uso do computador. Cabe ressaltar que o assalto ocorreu justamente no ponto em que a falante tenta convencer o seu parceiro conversacional do seu argumento, o que é indicado pelo trecho interrompido "você não acharia mais interessante". Os turnos anteriores reforçam essa ideia, pois apontam uma divergência de opiniões entre eles sobre o assunto, conforme o excerto (17).

(17) Dav: mas não dedi- num num... não iria desenvolver... (hes) uma parte da inteligência dessa criança?

Jos: desenvolveria por que não lê um livro também? como uma internet pode desenvolver um livro poderia desenvolver do mes- do mesmo jeito... talvez até melhor porque tava ilustrado... não ocorreria esses riscos todo

Dav: mas os tempos são outros

Em (18), temos o assalto ao turno realizado por Dav com postura de negação. Como este questiona a sinceridade da parceira conversacional em suas respostas dadas sobre o assunto conversar com os pais sobre assuntos íntimos, Jos sugere que ele pergunte para sua mãe, mas ele assalta o turno para se negar a fazer isso. Cabe ressaltar que esse é um momento de descontração, como sugere a presença dos risos.

(18) Jos: eu tô falando a verdade... depois cê pode conversar com ela e pode procurar saber se eu não sou uma pessoa

Dav: eu não vou dizer vou procurar saber depois diz que eu tô perseguindo o povo ((RISOS)) 
Os excertos (19) e (20) são exemplos das posturas de justificativa e de completar a fala do outro adotadas por Jos ao realizar o assalto ao turno. Em (19), embora ela faça uso do advérbio de negação, há uma justificativa para o que é dito em seu turno anterior sobre uso de roupas curtas.

(19) Dav: você é conservadora

Jos: eu sou... porque assim... são os meus princípios né? eu acho assim são os meus princípios né? cada um tem os seus mas meus princípios são esses... jamais eu sairia de minha casa com um pedaço de saia... com um pedaço de top... e ir pra uma praça... e ainda tar com um menino... na maior uma coisa uma coisa tão vulgar no meio de tantas pessoas... entendeu? porque assim eu me respeito

Dav: tem certeza que você não é evangélica?

Jos: absoluta ((RISOS))

Dav: ((RISOS)) cê falou assim parecendo [

Jos: não assim não querendo não querendo assim ser melhor do que ninguém mas eu eu tenho que me conservar eu tenho os meus princípios entendeu?

Já em (20), a mulher realiza o assalto enquanto o homem, abordando o tópico a cura gay, dá pistas por meio de pausa, que está buscando uma palavra; ela realiza, assim, o assalto com uma postura de completar a fala do outro.

(20) Dav: é tudo esse negócio aí... ((RISOS)) essa separação...cê não tá achando cê não acha que... (hes) dentro dessa ordem natural e daí é que vai se buscar essa cura... essa cura gay não tá baseada nessa busca... da... do que é o ideal? porque se o normal é homem com...

Jos: com mulher... e mulher com homem

Com relação ao domínio do tópico (como já mencionado, desta vez, Dav tinha os cartões que continham os assuntos a serem tratados), foi ele quem mais realizou assaltos também nessa interação; Jos não teve um comportamento de tentar dominar o tópico, devolvendo as perguntas ou mudando o assunto, como seu parceiro conversacional havia feito na interação em que não estava no domínio, ela se ateve a responder às perguntas, tendo realizado as três interrupções, já mencionadas, para completar a fala do outro e justificar-se quanto a informações apresentadas em turnos anteriores.

Quanto ao tipo de assalto ao turno, Dav realizou 3 com deixa e 2 sem deixa, e Jos 2 assaltos com deixa e um sem deixa; assim, nessa interação, tanto o falante homem quanto a mulher realizaram mais interrupções mediante a hesitação do seu parceiro conversacional.

A terceira, e última, interação analisada é um diálogo entre a mulher da primeira interação, Ama, e um indivíduo com o qual ela não tem uma relação de proximidade social, Wag. Nessa interação, diferentemente da primeira, ela não dispõe dos cartões com os assuntos a serem abordados, não estando com o domínio do tópico. 
Por meio da análise, foi possível constatar 8 ocorrências de assalto ao turno, sendo 4 realizadas por Wag e 4 por Ama; dos realizados pelo homem, 2 indicaram uma postura de completar a fala do outro; um foi utilizado para apresentar uma indagação e um para confirmação. Exemplos das posturas de completar a fala do outro, de indagação e de confirmação presentes nos assaltos realizados por Wag são apresentados nos excertos (21), (22) e (23) respectivamente.

(21) Wag: é... e em relação assim às redes sociais? como é que você vê? os assim... os pontos negativos e os pontos positivos... que ela trouxe... no mundo atual?

Ama: positivo é bom que a gente sempre tá atualizado né? sobre as coisa e tudo mais Wag: comunicação

(22) Wag: (hes) você sabe que hoje a nossa querida região nordeste... sofre... com um com um dos maiores... um dos piores fenômenos que existe que é a que o planeta pode ter que é a seca né? cê sabe que um ser vivo sem água não é nada

Ama: não sobrevivemos né?

Wag: mas assim você sabe que pra reverter isso é difícil porque se nós pudesse fazer chover n'era?

Ama: ((RISOS))

Wag: era bom mas... em relação às autoridades assim você acha que elas têm como tomar atitudes pelo menos pra amenizar... esse quadro?

Ama: tem... acho que essa [

Wag: tipo assim mandar ajuda?

(23) Wag: (hes) é o seguinte... no nosso grande comércio assim você já presenciou alguma vez uma cena assim... uma cena feia... de ver algum garoto assim de menor furtando alguma coisa?

Ama: não... presenciar mesmo eu não presenciei não mas eu fiquei sabendo assim de histórias de pessoas que já presenciou... e... muita das vezes através da mídia né? e questão assim de outras pessoas terem presenciado e ter me dito ter já conversado comigo e ter ficado assim né? bastante... perplexa pela situação de de vê ali naquela hora e às vezes não poder fazer nada... é uma questão realmente bem... tipo assim difícil né?

Wag: (est) é

Ama: pra pessoa que tá até presenciando... às vezes não é nem tanto pra quem tá praticando... mas eu nunca presenciei não

Wag: mas caso você um dia... presenciar... qua- qual será assim sua atitude? cê vai chegar pra esse menino dizer "olhe não faça isso" ou cê vai chegar pro dono?

Ama: eu não ia fa- assim não ia dizer nada não a ele pra não fazer porque a gente não sabe a reação de cada um né? hoje a violência tá tão

Wag: não é... isso é verdade

Em (21), diferentemente dos demais casos já apresentados que categorizamos como postura de completar a fala do outro, Wag assalta o turno não em um contexto de planejamento verbal em que sua interlocutora estivesse buscando uma palavra, mas para complementar o conteúdo informacional apresentado por ela, introduzindo sem deixa o turno "comunicação" como um dos pontos positivos das redes sociais. Todavia, ele fez isso antes que ela apresentasse os pontos 
negativos, como ele havia solicitado. Já em (22), Wag realiza o assalto a um turno em que Ama responde a uma pergunta feita por ele sobre a seca no nordeste. Antes que ela finalize sua resposta, contudo, ele faz um assalto para indagação, completando a sua pergunta anterior e, ao mesmo tempo, sugerindo, ele mesmo, uma atitude por parte do governo que seria de enviar ajuda para a população. Em (23), o falante homem realiza o assalto para concordar com o que está sendo dito por sua parceira conversacional a respeito do tópico violência.

Já dos assaltos realizados pela mulher, três tiveram postura de confirmação e um de negação, conforme exemplificado nos excertos (24) e (25) respectivamente.

(24) Wag: essas coisa correr brincar na areia... uma uma menina era uma boneca... um negócio hoje

Ama: é verdade

(25) Wag: (hes) a em relação à sua primeira vez... assim ficou sabendo você e o seu namorado no caso...

Ama: passe pra outra eu prefiro

Em (24), Ama, com uma postura de confirmação, realiza o assalto para concordar com o que é dito por Wag a respeito do assunto brincadeiras de crianças, em que ele relata quais eram as brincadeiras de sua época. Já em (25) ela o realiza para se negar a responder à pergunta que ele estava formulando a respeito de sua primeira relação sexual. A negação nesse caso é em relação ao tópico, que ela pode ter considerado muito íntimo para tratar com alguém com quem não tem proximidade social.

Com relação ao domínio do tópico, nessa interação tanto o homem, que estava com o domínio, quanto a mulher, que não estava, realizaram a mesma quantidade de assaltos, quatro cada, diferentemente do que ocorreu nas duas interações anteriores em que o homem, estando ou não no domínio, interrompeu sua interlocutora mais vezes.

Já quanto ao tipo de assalto, sete foram sem deixa e um com deixa; esse último realizado pela mulher. Nessa interação, embora tenha realizado um assalto com deixa a mais que o homem, a mulher, diferentemente do que ocorreu nas demais, houve menor alternância entre a entrada brusca e a que ocorre diante da hesitação do parceiro conversacional, tendo apresentado tendência pela primeira.

\section{CONSIDERAÇÕES FINAIS}

A observação do fenômeno de assalto ao turno com a atenção para o seu contexto de ocorrência nos permitiu constatar que, no âmbito do corpus analisado no presente trabalho, as 
entradas não consentidas ou não requeridas no turno do outro, em muitos dos casos, não parecem indicar uma disputa pela fala, mas sim um meio de colaboração, de demonstrar envolvimento, deixando ainda mais evidente que a conversa é construída em conjunto pelos parceiros conversacionais. Esta pode ser uma característica sociocultural do meio universitário.

No entanto, ainda assim, a postura de tomar o turno para colaborar parece ser ainda mais realizada pelas mulheres, pois, como já apresentado, muitas das interrupções das duas mulheres nas interações analisadas ocorrem para completar a fala do parceiro conversacional quando ele dá pistas de que está realizando o planejamento verbal, bem como para demonstrar que estão de acordo com que está sendo dito. Isso não significa que elas também não tenham discordado durante as interações, mas raramente o fizeram por meio de assalto.

Já os homens das interações analisadas alternaram mais entre comportamentos colaborativos, como o de confirmar e completar a fala do outro, e comportamentos mais competitivos, de disputa pela palavra, como os de negar e mudar o tópico da conversa.

Com relação ao domínio do tópico, observamos que um dos falantes homens, Dav, realizou mais assaltos estando ou não no domínio da conversa, enquanto o outro, Wag, dispondo dos cartões que continham os tópicos a serem tratados, realizou a mesma quantidade que a mulher com a qual interagiu, o que pode indicar que, nas interações analisadas, o fato de o falante estar ou não no domínio do tópico não influenciou nas realizações de interrupções na fala do outro.

Com relação à proximidade social, que permite a comparação entre a realização do assalto ao turno por parte de Dav e Ama em uma interação com indivíduo próximo, na interação entre eles, e em interação com indivíduo distante socialmente, entre Dav e Jos e entre Ama e Wag, foi possível observar que Ama realizou menos assaltos ao interagir com o parceiro conversacional com quem tem intimidade e igual quantidade numa conversa com um interactante distante socialmente, enquanto Dav realizou mais assaltos ao turno que as mulheres com quem interagiu independente da proximidade social.

Por fim, sobre o tipo de assalto ao turno, no geral das três interações, as mulheres realizaram mais o assalto com deixa que os homens, que optaram mais pelos sem deixa, o que indica uma maior inclinação por parte delas a interromper quando o parceiro conversacional dá pistas de que está tendo uma certa dificuldade no desenvolvimento do tópico, o que mais uma vez indica uma postura de colaboração para o desenvolvimento da conversa.

Tais resultados reforçam que o trabalho interacional de homens e mulheres é diferenciado, o que se evidencia por meio dos recursos linguísticos empregados pelos interactantes, como os marcadores discursivos interacionais (a exemplo do "assim" e do "né?" utilizados por uma das 
mulheres para atenuar um assunto impositivo) e, como ilustramos nesta análise, também com as posturas de assalto ao turno.

\section{REFERÊNCIAS}

ARAUJO, Andréia Silva; SANTOS, Kelly Carine dos; FREITAG, Raquel Meister Ko. Redes sociais, variação linguística e polidez: procedimentos de coleta de dados. In: FREITAG, Raquel Meister Ko. (Org.). Metodologia de Coleta e Manipulação de Dados em Sociolinguística. São Paulo: Blücher, 2014, p. 99-116.

CAMERON, Deborah. Performing Gender Identity: Young Men's Talk and the Construction of Hetersexual masculinity. In: COATES, J. Language and Gender. Malden: Blackwell Publishing, 1998.

CARLI, Linda L. Gender, language, and influence. Journal of Personality and Social Psychology, v. 59, n. 5, p. 941, 1990.

COATES, Jennifer. Language and gender: A reader. Oxford: Blackwell, 1998.

COULTHARD, Malcolm. Linguagem e sexo. São Paulo: Ática, 1991.

ECKERT, Penelope. The whole woman: Sex and gender differences in variation. Language variation and change, v. 1, n. 3, p. 245-267, 1989.

FREITAG, Raquel Meister Ko; SEVERO, Cristine Gorski. Mulheres, Linguagem e Poder - Estudos de Gênero na Sociolinguística Brasileira. São Paulo: Blucher, 2015.

FREITAG, Raquel Meister Ko. (Re)Discutindo Sexo/Gênero na Sociolinguística. In: FREITAG, R. M. K. SEVERO, C. G. (org.). Mulheres, Linguagem e Poder - Estudos de Gênero na Sociolinguística Brasileira. São Paulo: Blucher, 2015, p. 17-74.

FREITAG, Raquel Meister Ko. Banco de dados falares sergipanos. In: Working Paper em Linguística, v. 14, p. 156-164, 2013.

FREITAG, Raquel Meister Ko.; SILVA, Rosangela Barros da; EVANGELISTA, Flávia Regina de Santana. Marcadores discursivos interacionais: diferentes metodologias, diferentes resultados. Diacrítica, v. 31, n. 1, p. 20, 2017.

GALEMBECK, Paulo de Tarso; COSTA, Nonalíssia Silva da. Alternância e participação: a distribuição de turnos na interação simétrica. In: CELLI - Colóquio de Estudos Linguísticos e Literários, v. 3, 2007, Maringá. Anais... Maringá, 2009, p. 1937-1944.

GALEMBECK, Paulo de Tarso. O turno conversacional. In: PRETI, D. (Org.). Análise de textos orais. São Paulo: FFLCHUSP, 1999. p.55-79.

LAKOFF, Robin. Linguagem e lugar da mulher. (1973). In: OSTERMANN, A. C.; FONTANA, B. F. Linguagem. Gênero. Sexualidade. Clássicos traduzidos. São Paulo: Parábola Editorial, 2010, p. 13-30.

LABOV, William. The intersection of sex and social class in the course of linguistic change. Language variation and change, v. 2, n. 2, p. 205-254, 1990. 
MACEDO, Alzira Tavares; SILVA, Gisele Machline Oliveira. Análise sociolinguística de alguns marcadores conversacionais. In: MACEDO, A.T.; RONCARATI, C.; MOLICA, M. C. (org.). Variação e discurso. Rio de Janeiro: Tempo Brasileiro, 1996, p. 11-50.

JUNG, Neiva Maria; MAREGA, Larissa Minuessa Pontes. A sobreposição de falas na conversa cotidiana: disputa pela palavra?. Veredas, v. 1, p. 321-337, 2011.

OSTERMANN, Ana Cristina. Análise da conversa: o estudo da fala-em-interação. In: OSTERMANN, Ana Cristina; MENEGHEL, Stela Nazareth (Org). Humanização, gênero, poder: contribuições dos estudos de fala-em-interação para a atenção à saúde. Rio de Janeiro: Editora Fiocruz/Campinas: Mercado de Letras, 2012, p. 33-43.

REID, Scott A.; KEERIE, Natasha; PALOMARES, Nicholas A. Language, gender salience, and social influence. Journal of Language and Social Psychology, v. 22, n. 2, p. 210-233, 2003.

SANTANA, Rebeca Rodrigues de. Interrupção/assalto ao turno, o papel do gênero e o efeito cultural. Cadernos de Pós Graduação em Letras, v. 18, n. 1, p. 55-74, 2018.

SANTANA, Rebeca Rodrigues de. Tipos de tipo em uma comunidade de práticas universitária. 2019. Dissertação (Mestrado em Letras). Universidade Federal de Sergipe, 2019.

TANNEN, Deborah. Quem está interrompendo? Questões de dominação e controle. In:

OSTERMANN, A. C.; FONTANA, B. (org.). Linguagem, sexo, sexualidade. São Paulo: Parábola Editorial, 2010, p. 67-92.

TANNEN, Deborah. You just don't understand: Women and men in conversation. London: Virago, 1991.

ZIMMERMAN, Don H; WEST, Candace. Pequenos insultos: interrupções em conversas entre pessoas desconhecidas e de diferentes sexos. In: OSTERMANN, A. C.; FONTANA, B. (org.). Linguagem, sexo, sexualidade. São Paulo: Parábola Editorial, 2010, p. 49-66.

WEST, Candace; ZIMMERMAN, Don H. Small insults: A study of interruptions in cross-sex conversations between unacquainted persons. Language, gender and society, p. 102-117, 1983. 